Revista Destaques Acadêmicos, Lajeado, v. 12, n. 3, 2020. ISSN 2176-3070

DOI: http://dx.doi.org/10.22410/issn.2176-3070.v12i3a2020.2686

http://www.univates.br/revistas

\title{
COMO MINIMIZAR PERDA DE NUTRIENTE EM UNIDADES DE ALIMENTAÇÃO E NUTRIÇÃO
}

\author{
Bárbara Domingues Formaggio ${ }^{1}$, Kauana Multini de Almeida ${ }^{1}$, \\ Larissa Canton Gonçalves ${ }^{1}$, Fernanda Ferreira Corrêa ${ }^{2}$
}

Resumo: Em todas as fases de seu processamento, os alimentos estão suscetíveis a perda de valor nutricional. Em Unidades de Alimentação e Nutrição são utilizados diversos tipos de processamentos, destacando a cocção, resfriamento e congelamento. O estudo tem como propósito avaliar a perda de nutrientes que ocorrem em processos de manipulação e preparo, e a importância de sua minimização em Unidades de Alimentação e Nutrição. Omesmo foi realizado através de um levantamento bibliográfico por meio das bases de dados ScieELO e LILACS. Considerou-se para a busca apenas artigos originais publicados a partir de 1998, nacionais e internacionais. Após a seleção dos artigos, 18 fizeram parte desse estudo e preencheram os critérios inicialmente propostos. Os alimentos contêm atividade biológica, levando à perda de qualidade e redução da vida de prateleira. A cocção dos alimentos, é um processo que utiliza calor através equipamentos, causando perda de diversos nutrientes. Já na refrigeração, a perda de nutrientes acontece com alimentos sensíveis ao frio e nas temperaturas mais baixas. A severidade do dano por congelamento é afetada pela combinação de tempo e temperatura. $\mathrm{O}$ branqueamento é um método utilizado para manter a qualidade dos alimentos; porém, há controvérsias nos estudos sobre esse processo nos alimentos. Conclui-se que a partir dos estudos é possível identificar a maior eficácia na manutenção de nutrientes em alguns métodos de preparo e conservação dos alimentos. Aqueles que apresentaram menores perdas nutricionais são o cozimento por vapor através do forno combinado e congelamento rápido, enquanto o branqueamento apresenta perdas nutricionais inevitáveis. Através da análise dos métodos, os equipamentos necessários e seus custos, foi possível afirmar a viabilidade na realização de procedimentos que minimizam a perda de nutrientes durante a produção nas Unidades de Alimentação e Nutrição, podendo trazer mais benefícios a unidade.

Palavras-chave: Nutrientes; Tecnologia de alimentos; Serviços de alimentação.

1 Graduandas do curso de Nutrição do Centro Universitário São Camilo.

2 Nutricionista, Doutora, Docente do curso de Nutrição do Centro Universitário São Camilo. 


\section{INTRODUÇÃO}

As Unidades de Alimentação e Nutrição devem oferecer uma alimentação adequada para seus clientes, com o objetivo de manter a saúde dos mesmos. A alimentação atende certos requisitos, como o equilíbrio em nutrientes, de acordo com os hábitos alimentares dos clientes, e o aspecto higiênico, respeitando a disponibilidade financeira da UAN (ABREU; PINTO; SPINELLI, 2009). Isto é importante principalmente para as unidades que participam do Programa de Alimentação do Trabalhador, o qual tem como objetivo melhorar a situação nutricional dos trabalhadores, promovendo sua saúde e prevenindo doenças profissionais (BRASIL, 2002). Além disso, os consumidores estão cada vez mais conscientes e exigentes, buscando alimentos seguros e com praticidade, para adequação às diversas rotinas aceleradas do dia-a-dia (BRASIL, 2014).

De acordo com o Guia Alimentar (BRASIL, 2014) a alimentação diz respeito à ingestão de nutrientes, como também aos alimentos que contém e fornecem os mesmos, incluindo como os alimentos são preparados e combinados entre si, formando aspectos que influenciam a saúde e o bem-estar. Os alimentos de origem vegetal, como as hortaliças e frutas, desempenham um importante papel na alimentação humana devido ao valor nutricional. A Organização Mundial de Saúde (OMS) alerta que o consumo insuficiente de frutas e hortaliças $(\mathrm{FH})$ está associado ao maior risco de mortalidade e ocorrência de doenças crônicas não transmissíveis (PIGOLI, 2012; BRASIL, 2010; WHO, 2011).

Esses alimentos são, então, compostos por diversos nutrientes, tais como proteínas, carboidratos, lipídios, minerais, vitaminas, água, oxigênio e fibra, os quais são importantes para diversas atividades biológicas. Deste modo, a baixa ingestão ou não aproveitamento de nutrientes pode causar enfermidades carenciais. Em todas as fases de seu processamento, os alimentos estão suscetíveis a perda de valor nutricional. A relevância da tecnologia de alimentos está no desenvolvimento de métodos de processos que possam reduzir as perdas, aumentando a vida de prateleira desses alimentos, sem renunciar às qualidades físicas, químicas e biológicas (CEARÁ, 2013; NESPOLO, 2015).

Para a produção de refeições em Unidades de Alimentação e Nutrição são utilizados diversos equipamentos, destacando os utilizados para cocção, resfriamento e congelamento dos alimentos (PROENÇA, 2009). Os métodos de cocção são apontados como sendo um dos principais determinantes das perdas de nutrientes em vegetais. Já na refrigeração os impactos sobre as propriedades nutricionais e sensoriais dos alimentos são menores. Quando ocorre o descongelamento, grandes quantidades de fluidos celulares são liberadas, provocando alterações na qualidade nutricional e organolépticas, sendo essas perdas de nutrientes, como vitaminas hidrossolúveis, sais minerais e proteínas, e modificações de textura e na aparência (ALVES et al., 2011). 
A perda de nutrientes em Unidades de Alimentação e Nutrição, e como as mesmas lidam com isso, é um tema de grande relevância, o qual apresenta uma escassez de estudos, demonstrando a importância de novos conteúdos sobre.

Este estudo tem como propósito avaliar a perda de nutrientes que ocorre em processos de manipulação e preparo, e a importância de sua minimização em Unidades de Alimentação e Nutrição.

\section{MÉTODOS}

Trata-se de uma pesquisa de revisão bibliográfica do tipo narrativa, realizada por meio da busca de artigos científicos, tendo como fontes as seguintes bases de dados: ScieELO e LILACS. Utilizou-se como descritores na busca bibliográfica: métodos de cocção, avaliação sensorial, perda nutricional, refrigeração e congelamento, processamento, nutrientes, degradação térmica, tecnologia dos alimentos, e serviços de alimentação, além do operador booleano AND. Considerou-se para a busca apenas artigos originais publicados a partir de 1998, nacionais e internacionais. Somando-se todas as bases de dados, foram encontrados 79 artigos. Após a leitura dos títulos dos artigos, notou-se que alguns deles se repetiram nas diferentes bases de dados. Foram selecionados 34 artigos para a leitura do resumo e excluídos, artigos de revisão e os que não diziam respeito ao propósito deste estudo. Após a leitura dos resumos, foram selecionados 18 artigos que preenchiam os critérios inicialmente propostos e que foram lidos na íntegra, bem como, publicações do Ministério da Agricultura, Pecuária e Abastecimento, Secretaria da Educação, e Secretária de Inspeção do Trabalho, além de manuais e livros acadêmicos relacionados ao tema da perda de nutrientes em Unidades de Alimentação e Nutrição.

Segue abaixo um quadro com os estudos selecionados para esse trabalho.

Quadro 1. Artigos utilizados no estudo, de acordo com autor, data, título e objetivo.

\begin{tabular}{|l|l|l|}
\hline AUTOR E ANO & \multicolumn{1}{|c|}{ TÍTULO } & \multicolumn{1}{c|}{ OBJETIVO } \\
\hline ALVES et al., 2011 & $\begin{array}{l}\text { Efeito dos diferentes } \\
\text { métodos de cocção } \\
\text { sobre os teores } \\
\text { de nutrientes em } \\
\text { brócolis }\end{array}$ & $\begin{array}{l}\text { Verificar a influência de diferentes } \\
\text { métodos de cocção na preservação de } \\
\text { nutrientes presentes nos brócolis }\end{array}$ \\
\hline CARNEIRO, 2004 & $\begin{array}{l}\text { Comida e sociedade: } \\
\text { uma história da } \\
\text { alimentação }\end{array}$ & $\begin{array}{l}\text { Refletir acerca da multiplicidade de } \\
\text { caminhos passíveis de serem percorridos } \\
\text { no estudo da alimentação. }\end{array}$ \\
\hline
\end{tabular}




\begin{tabular}{|c|c|c|}
\hline AUTOR E ANO & TÍTULO & OBJETIVO \\
\hline COLLAÇO, 2004 & $\begin{array}{l}\text { Restaurantes de } \\
\text { comida rápida, os } \\
\text { fast-foods, em praças } \\
\text { de alimentação de } \\
\text { shopping centers: } \\
\text { transformações no } \\
\text { comer. }\end{array}$ & $\begin{array}{l}\text { Interpretar algumas dessas } \\
\text { transformações, tendo como recorte } \\
\text { empírico três praças de alimentação } \\
\text { localizadas em shopping centers da } \\
\text { cidade de São Paulo. A partir da dinâmica } \\
\text { social notada entre os consumidores } \\
\text { de fast-food desses espaços, pretende- } \\
\text { se analisar as formas como as escolhas } \\
\text { pessoais associadas ao ato de comer. }\end{array}$ \\
\hline $\begin{array}{l}\text { DAIUTO et al., } \\
2015\end{array}$ & $\begin{array}{l}\text { Estabilidade } \\
\text { de Minerais } \\
\text { em Hortaliças } \\
\text { submetidas a } \\
\text { diferentes métodos } \\
\text { de cozimento. }\end{array}$ & $\begin{array}{l}\text { Verificar o método de cozimento mais } \\
\text { adequado para o preparo de hortaliças, } \\
\text { visando minimizar as perdas de minerais. } \\
\text { Partes convencionais e não convencionais } \\
\text { de abóbora, brócolis, cenoura e couve- } \\
\text { flor foram submetidas a quatro tipos de } \\
\text { tratamentos térmicos (imersão, vapor e } \\
\text { micro-ondas). }\end{array}$ \\
\hline $\begin{array}{l}\text { DANG; ARCOT; } \\
\text { SHRESTHA, } 2000\end{array}$ & $\begin{array}{l}\text { Folate retention in } \\
\text { selected processed } \\
\text { legumes }\end{array}$ & $\begin{array}{l}\text { Determinar a estabilidade dos folatos } \\
\text { durante o processamento de ervilhas e } \\
\text { grão de bico. }\end{array}$ \\
\hline ESTELLES, 2003 & $\begin{array}{l}\text { Importância } \\
\text { do controle da } \\
\text { temperatura e do } \\
\text { tratamento térmico } \\
\text { na preservação } \\
\text { dos nutrientes e } \\
\text { da qualidade dos } \\
\text { alimentos. }\end{array}$ & $\begin{array}{l}\text { Avaliar a importância do controle da } \\
\text { temperatura e do tratamento térmico na } \\
\text { preservação dos nutrientes e da qualidade } \\
\text { dos alimentos. }\end{array}$ \\
\hline $\begin{array}{l}\text { GONÇALVES; } \\
\text { ANDRADE; } \\
\text { SOUZA, } 2010\end{array}$ & $\begin{array}{l}\text { Influência do } \\
\text { branqueamento } \\
\text { nas características } \\
\text { físico químicas e } \\
\text { sensoriais do abacaxi } \\
\text { desidratado*. } \\
\end{array}$ & $\begin{array}{l}\text { Avaliar as características físicas e } \\
\text { químicas do abacaxi e o efeito do } \\
\text { branqueamento no fruto desidratado, } \\
\text { a fim de investigar tecnologia para o } \\
\text { abacaxi Pérola produzido no Amazonas. }\end{array}$ \\
\hline $\begin{array}{l}\text { MELO; SOUZA; } \\
\text { ARAÚJO, } 2013\end{array}$ & $\begin{array}{l}\text { Custos da qualidade: } \\
\text { um estudo em um } \\
\text { restaurante de } \\
\text { grande porte da } \\
\text { cidade de Natal -RN }\end{array}$ & $\begin{array}{l}\text { Mensurar os custos da qualidade de um } \\
\text { restaurante de grande porte localizado na } \\
\text { cidade de Natal-RN. }\end{array}$ \\
\hline MONTEIRO, 2014 & $\begin{array}{l}\text { Determinação das } \\
\text { melhores técnicas } \\
\text { de cocção para } \\
\text { aceitabilidade de } \\
\text { hortaliças }\end{array}$ & $\begin{array}{l}\text { Determinar melhores técnicas de cocção } \\
\text { para aceitabilidade de hortaliças. }\end{array}$ \\
\hline $\begin{array}{l}\text { OETTERER; } \\
\text { SAVAY-DA- } \\
\text { SILVA; GALVÃO, } \\
2012\end{array}$ & $\begin{array}{l}\text { Congelamento é o } \\
\text { melhor método para } \\
\text { a conservação do } \\
\text { pescado }\end{array}$ & Não especifica \\
\hline
\end{tabular}




\begin{tabular}{|c|c|c|}
\hline AUTOR E ANO & TÍTULO & OBJETIVO \\
\hline PIGOLI, 2012 & \begin{tabular}{|l|} 
Alterações \\
nutricionais \\
em hortaliças \\
decorrentes de \\
diferentes métodos \\
de cozimento \\
\end{tabular} & $\begin{array}{l}\text { Verificar o método de cozimento mais } \\
\text { adequado para o preparo da cenoura (cv } \\
\text { Nantes), visando minimizar as perdas } \\
\text { nutricionais. }\end{array}$ \\
\hline SAGGIN, 2017 & $\begin{array}{l}\text { Avaliaçãa Físico- } \\
\text { Química de } \\
\text { Hortaliças Orgânicas } \\
\text { Congeladas }\end{array}$ & $\begin{array}{l}\text { Avaliar a qualidade físico-química } \\
\text { e nutricional de brócolis, cenoura e } \\
\text { couve-flor orgânico cultivadas na região } \\
\text { noroeste do estado do Rio Grande do } \\
\text { Sul, após o processo de branqueamento e } \\
\text { congelamento. } \\
\end{array}$ \\
\hline $\begin{array}{l}\text { SANTOS; ABREU; } \\
\text { CARVALHO, } \\
2003\end{array}$ & $\begin{array}{l}\text { Efeito de diferentes } \\
\text { tempos de cozimento } \\
\text { nos teores de } \\
\text { minerais em folhas } \\
\text { de brócolis, couve- } \\
\text { flor e couve (Brassica } \\
\text { oleracea L.) }\end{array}$ & $\begin{array}{l}\text { Verificar a utilização total das brássicas na } \\
\text { alimentação humana. }\end{array}$ \\
\hline $\begin{array}{l}\text { SOARES; JOSÉ, } \\
2013\end{array}$ & $\begin{array}{l}\text { Compostos bioativos } \\
\text { em polpas de mangas } \\
\text { "rosa" e "espada" } \\
\text { submetidas ao } \\
\text { branqueamento e } \\
\text { congelamento }\end{array}$ & $\begin{array}{l}\text { Analisar a influência do branqueamento } \\
\text { e do congelamento sobre os teores de } \\
\text { carotenoides totais e ácido ascórbico em } \\
\text { mangas 'Rosa' e 'Espada' em relação ao } \\
\text { tempo de armazenamento }\end{array}$ \\
\hline $\begin{array}{l}\text { SOUZA et al., } \\
2013\end{array}$ & $\begin{array}{l}\text { Emprego do frio } \\
\text { na conservação de } \\
\text { alimentos }\end{array}$ & $\begin{array}{l}\text { Discorrer sobre os principais pontos do } \\
\text { emprego do frio na conservação dos } \\
\text { alimentos, custo da cadeia do frio, injúrias } \\
\text { causadas pelo frio, pré-tratamentos que } \\
\text { podem ser aplicados e embalagens que } \\
\text { devem ser utilizadas. }\end{array}$ \\
\hline $\begin{array}{l}\text { SOUZA FILHO et } \\
\text { al., } 1999\end{array}$ & $\begin{array}{l}\text { Efeito do } \\
\text { branqueamento, } \\
\text { processo osmótico, } \\
\text { tratamento térmico } \\
\text { e armazenamento } \\
\text { na estabilidade } \\
\text { da vitamina C de } \\
\text { pedúnculos de } \\
\text { caju processados } \\
\text { por métodos } \\
\text { combinados. } \\
\end{array}$ & $\begin{array}{l}\text { Avaliar o emprego da tecnologia de } \\
\text { obstáculos na conservação de pedúnculos } \\
\text { de caju por métodos combinados e o } \\
\text { efeito na perda de vitamina C das várias } \\
\text { etapas do processamento, assim como do } \\
\text { armazenamento do produto processado } \\
\text { pelo período de } 60 \text { dias. }\end{array}$ \\
\hline $\begin{array}{l}\text { VASCONCELOS; } \\
\text { FILHO, } 2010\end{array}$ & $\begin{array}{l}\text { Conservação de } \\
\text { alimentos }\end{array}$ & $\begin{array}{l}\text { Definir conservação de alimentos e } \\
\text { identificar a importância dos métodos } \\
\text { gerais de preservação de alimentos. }\end{array}$ \\
\hline
\end{tabular}




\begin{tabular}{|l|l|l|}
\hline AUTOR E ANO & \multicolumn{1}{|c|}{ TÍTULO } & \multicolumn{1}{c|}{ OBJETIVO } \\
\hline & $\begin{array}{l}\text { Avaliação da } \\
\text { Retenção de } \\
\text { Nutrientes, } \\
\text { Aspectos Sensoriais } \\
\text { e Microbiológicos } \\
\text { de Batata-doce } \\
\text { VELHO, } 2016\end{array}$ & $\begin{array}{l}\text { Avaliar a retenção de nutrientes em } \\
\text { batatas-doces submetidas a métodos de } \\
\text { cocção convencionais (ebuliçãa, vapor, } \\
\text { forno convencional e panela de pressão) } \\
\text { e contemporâneos (forno de micro- } \\
\text { ondas e a vácuo no forno combinado), } \\
\text { Diferentes Método a } \\
\text { ale Cocção de avaliar a aceitação sensorial e as } \\
\text { características microbiológicas de cada } \\
\text { método. }\end{array}$ \\
\hline
\end{tabular}

\section{DESENVOLVIMENTO}

A alimentação é, após a respiração e a ingestão de água, a mais básica das necessidades humanas (CARNEIRO, 2004). Com o ritmo de vida urbana, aumentou-se a prática de fazer refeições fora de casa e atualmente uma das maiores preocupações da população é a saúde. Deste modo, os consumidores estão cada vez mais conscientes e exigentes, buscando alimentos seguros, saudáveis e com praticidade, para adequação às diversas rotinas aceleradas do dia-a-dia, demonstrando a importância dos restaurantes na atualidade (COLLAÇO, 2004; CONGRESSO NORTE NORDESTE DE PESQUISA E INOVAÇÃO, 2012; NESPOLO, 2015).

Os alimentos contêm atividade biológica, levando à perda de qualidade e redução da vida de prateleira. Em todas as fases de seu processamento, os alimentos estão suscetíveis a processos deteriorantes e de contaminação, causadas principalmente por microrganismos, enzimas e reações do oxigênio com o alimento, modificando suas estruturas primárias (NESPOLO, 2015).

A relevância da tecnologia de alimentos está no desenvolvimento de métodos e processos que possam reduzir as perdas de nutrientes, aumentando o aproveitamento de subprodutos e também a disponibilidade de alimentos, ampliando sua "vida de prateleira" sem abrir mão da qualidade (GAVA, 2008; NESPOLO, 2015).

Os principais métodos utilizados nos processos dentro de uma Unidade de Alimentação e Nutrição são: cocção, congelamento e refrigeração, além do branqueamento, para isso, faremos uma revisão analisando todos esses métodos.

\subsection{Cocção}

A cocção dos alimentos, é um processo que utiliza calor, promove trocas químicas, físico-químicas e estruturais nos componentes dos alimentos. Ocorre também a destruição dos microrganismos e enzimas, além da modificação das propriedades sensoriais e nutricionais, devido ao tempo e a temperatura 
empregada. A cocção desagrega as estruturas vegetais, melhorando a palatabilidade e a digestibilidade, além de promover um melhor aspeto, aumentando a vontade do indivíduo em experimentar a refeição. (ARAÚJO et al., 2014). Portanto, são utilizados diversos equipamentos com o objetivo de assar, fritar, grelhar, gratinar, aquecer, cozinhar em banho-maria e a vapor, entre outros métodos (PROENÇA, 2009).

Entretanto, através dessa exposição ao calor, pode haver a perda de diversos nutrientes, como o Ácido Ascórbico, que oxida principalmente na exposição ao calor, o Potássio, que tem seu teor reduzido à $60 \%$ através do cozimento, e o Betacaroteno, que reduz através do excesso de aquecimento, principalmente pelo forno de micro-ondas (PHILIPPI, 2014). Essa diminuição de Ácido Ascórbico é demonstrada no estudo de Velho (2016), de modo que esta ocorreu em todos os métodos de cocção testados, mas principalmente na cocção por panela de pressão, no forno e no micro-ondas, tendo menores perdas na cocção à vácuo no forno combinado e por ebulição.

Outro exemplo disso, são os Folatos. O estudo de Dang, Arcot e Shrestha (2000) investigou efeitos de fervura, imersão e cozimento em pressão, mostrando que há efeitos em diferentes métodos de cozimento na retenção de folatos em leguminosas. Um de seus resultados de suas análises revelaram uma diminuição significativa de $51 \%$ e $56 \%$ no teor de folato em espinafre e brócolis, respectivamente, em comparação aos valores dos alimentos crus. Por outro lado, o cozimento do espinafre e brócolis no vapor, não resultaram uma perda significante do conteúdo de folato, quando também comparado aos alimentos crus.

A imersão é um método que utiliza calor úmido, e é caracterizado pela submersão do alimento meio aquoso, que precisa estar fervente (ARAÚJO et al., 2014). A imersão manteve os teores de Ferro, Cálcio e Magnésio no estudo de Daiuto et al. (2015) na cocção da casca e polpa da abóbora, entretanto apresentou alta perda de Fósforo e Potássio na polpa da abóbora. Evidenciando que o mesmo método de cozimento pode interagir diferentemente com cada micronutriente distinto.

A cocção por micro-ondas é capaz de aquecer os alimentos rapidamente através da radiação por meio de ondas curtas de alta frequência, não havendo contato direto com a fonte de calor, garantindo qualidades microbiológicas e sanitárias dos alimentos (GERMANO; GERMANO, 2011; INSTITUTO AMERICANO DE CULINÁRIA, 2011). O estudo de Daiuto et al. (2015) demonstrou a manutenção de Potássio, Cálcio e Magnésio no cozimento de abóbora, todavia, com perdas significativas de Ferro. Na cozedura do brócolis houve a manutenção do Ferro e Zinco, e perda significativa dos demais nutrientes, como Potássio, Fósforo, Cálcio e Magnésio. Isto indica que o mesmo método de cocção também pode interagir de maneira diferente com os mesmos nutrientes dependendo do alimento em que se encontram. 
As perdas de micronutrientes no cozimento ocorrem através da lixiviação e a fácil oxidação de nutrientes específicos, como a Vitamina C, em altas temperaturas e no contato com oxigênio (ALVES et al., 2011). Deste modo, a redução de micronutrientes está associada ao tempo de cocção, à temperatura, ao contato direto com água e a proporção da mesma em relação ao alimento, sendo necessário utilizar menores quantidades de água e o tempo de cocção deve ser breve para minimizar a perda de nutrientes (ALVES et al., 2011; LIVERA; SALGADO, 2007; PHILIPPI, 2014; SANTOS; ABREU; CARVALHO, 2003).

A melhor manutenção dos nutrientes após a cocção ocorreu através do forno combinado e da cocção a vapor. O forno combinado utiliza o calor seco e úmido para a cocção dos alimentos em menores temperaturas, preservando as características sensoriais e nutricionais dos alimentos (PROENÇA, 2009). Este método apresentou a melhor preservação de Fósforo e Vitamina C. A cocção a vapor é um método que também preserva estas características, a qual preserva Potássio, Cálcio, Fósforo, Vitamina C, Ferro, Folato, Magnésio e Zinco, diminuindo as perdas por difusão ou lixiviação através da menor temperatura presente no vapor da água quando comparado com a própria água que gera o calor (ALVES et al., 2011; DAIUTO et al., 2015; DANG; ARCOT; SHRESTHA, 2000).

\subsection{Congelamento e refrigeração}

A refrigeração $\left(-1,5^{\circ} \mathrm{C}\right.$ a $\left.10^{\circ} \mathrm{C}\right)$ é utilizada de forma temporária até que se aplique outro método ou até quando o alimento seja consumido. Neste método não há eliminação de microrganismos, somente inibição do seu ciclo de reprodução, retardando a deterioração dos alimentos quando atacados, mantendo a qualidade original do alimento e prolongando sua vida útil. Alguns alimentos são sensíveis ao frio (principalmente frutas e hortaliças) nos quais sofrem danos pela baixa temperatura (entre $10^{\circ} \mathrm{C}$ e $13^{\circ} \mathrm{C}$ ), como o murchamento das folhas, lesões superficiais, alterações da cor, perda de firmeza e crocância em frutas e hortaliças, envelhecimento, aglomeração dos produtos em pó e até liberação de produtos voláteis, como na cebola, alho, pescados e frutas, enquanto outros alimentos são suscetíveis a absorvê-los como o leite e derivados (AZEREDO, 2012).

$\mathrm{O}$ congelamento $\left(40^{\circ} \mathrm{C}\right.$ a $\left.-10^{\circ} \mathrm{C}\right)$ é obtido por um efeito combinado de baixas temperaturas e baixa atividade de água (EVANGELISTA, 2000). As gorduras e proteínas são os macronutrientes mais susceptíveis a modificações dos aspectos nutritivos e sensoriais, assim como as verduras e frutas, durante o armazenamento (principalmente sob $-18^{\circ} \mathrm{C}$ por um período prolongado de um ano ou mais). Os alimentos geralmente perdem rigidez e se tornam pegajoso após o descongelamento. A severidade do dano por congelamento é afetada pela combinação de tempo e temperatura, assim como ocorre o dano pelo frio (CESAR, 2008; AZEREDO, 2012). 
Oetterer e colaboradores, 2012, encontraram como resultado em pescados congelados, uma perda de nutrientes e oxidação de ácidos graxos, como o Ômega 3 na estocagem e no descongelamento quando os mesmos não forem realizados de forma correta. Esse estudo mostrou também que o congelamento também pode levar à perda das propriedades funcionais das proteínas.

$\mathrm{O}$ congelamento rápido (geralmente $-25^{\circ} \mathrm{C}$ a $-40^{\circ} \mathrm{C}$ ) acontece quando queda de temperatura é muito brusca, congelando a água imediatamente. Esse processo é ideal, pois ao descongelar, o alimento reassume suas condições iniciais sem que haja perda significativa de nutrientes e de propriedades sensoriais. Após o congelamento, a armazenagem é feita a $18^{\circ} \mathrm{C}$ (SOUZA et al., 2013).

\subsection{Branqueamento}

O branqueamento é um método de conservação no qual consiste em aquecer o vegetal durante 1 a 5 minutos $\left(70\right.$ a $\left.100^{\circ} \mathrm{C}\right)$, e posteriormente, realizar um resfriamento, evitando cozimento do alimento, acontecendo assim a inativação de enzimas que causaria deterioração e/ou degradação de nutrientes dos alimentos (ESTELLES, 2003; FELOWS, 2006). Quando o branqueamento não for suficiente observa-se: o escurecimento de frutas e hortaliças; desenvolvimento de sabores e odores estranhos; alteração do sabor e da textura de carnes armazenadas por longo período e perdas de componentes solúveis (VASCONCELOS; FILHO, 2010).

Gonçalves, Andrade e Souza (2010) mostraram que se o branqueamento for feito de maneira eficaz e eficiente, trará resultados benéficos, como a remoção do ar no interior do alimento, além de favorecer a fixação da cor e acentuá-la, reduzir o número de microrganismos contaminantes e melhorar a textura do alimento. De acordo com Oetterer et al. (2006), o método tem sido recomendado por sua menor taxa de lixiviação, entretanto alguns estudos apresentam o contrário. Saggin (2017) aponta a diminuição na concentração de polifenóis nos alimentos, Souza Filho et al. (1999), e Soares e José (2013) expõem a degradação de vitamina $C$ e carotenoides, relacionadas principalmente com o tempo de imersão em água.

De acordo com Oetterer et al. (2006), o método tem sido recomendado por sua menor taxa de lixiviação, entretanto estudos apresentam o contrário. Saggin (2017) aponta a diminuição na concentração de polifenóis nos alimentos, Souza Filho et al. (1999), e Soares e José (2013) expõem a degradação de vitamina C e carotenoides, relacionadas principalmente com o tempo de imersão em água. 


\subsection{Unidades de alimentação e nutrição}

As UANs tratam-se de unidades de trabalho ou órgãos de uma empresa que desempenham atividades relacionadas à alimentação. São estruturas destinadas à preparação e fornecimento de refeições, atentando para uma produção de qualidade que atenda às necessidades dos clientes nos aspectos nutricionais, higiênicos sanitários, sociais e também culturais (NONINO; FERREIRA; TANAKA, 2012). A partir dos artigos antecedentes é possível identificar a maior eficácia na manutenção de nutrientes em alguns métodos de preparo e conservação dos alimentos.

Dentre os equipamentos utilizados para a cocção em Unidades de Alimentação e Nutrição, Proença (2009) aponta que o forno combinado engloba todos os métodos de cocção, reduzindo o tempo de preparo e o desperdício. Este utiliza tanto do calor seco quanto o úmido para a cocção, evitando ressecamento e preservando características sensoriais e nutricionais. Além disso, Alves et al. (2011) mostraram que uma menor temperatura para cozimento sem imersão em água minimiza as perdas de micronutrientes por oxidação e lixiviação. De acordo com Melo, Souza e Araújo (2013), o equipamento é de alto custo, necessitando de um alto investimento, todavia, o uso deste leva à economias de tempo, energia, água e mão de obra, além de evitar desperdícios relacionado ao mau preparo dos alimentos e possibilitar a cocção de diferentes alimentos simultaneamente, sem alterar os sabores. Logo, a utilização deste equipamento em Unidades de Alimentação e Nutrição é possível para aqueles que dispõem de uma alta quantia para investir, possibilitando uma futura economia nos demais aspectos apresentados anteriormente, além da produção de refeições mais saudáveis e ricas em vitaminas e minerais.

A cocção por vapor é um método rápido e eficiente, possivelmente aplicado em diversos alimentos. Também demonstra preservar as características sensoriais, como o sabor dos alimentos, e diversos nutrientes (MCGEE, 2014; PHILIPPI, 2014). Pode ser realizado através do próprio forno combinado (MELO; SOUZA; ARAÚJO, 2013) e pelo procedimento tradicional (MONTEIRO, 2014). Portanto, este método de cocção também é viável para UAN, de modo que este pode ser realizado através do forno combinado em unidades com alto poder aquisitivo, ou através da técnica tradicional em unidades que buscam menores gastos relacionados à equipamentos.

O melhor método de congelamento é o processo rápido, o qual congela a água do alimento rapidamente e de modo eficaz, evitando a danificação das membranas celulares. Deste modo, na hora do descongelamento as perdas nutricionais não são significativas (SOUZA et al., 2013). Entretanto, de acordo com Silva (2000), o congelamento é um método de conservação de alto custo, por conta da aquisição e manutenção dos equipamentos. Isto posto, este procedimento também é possível de ser realizado em Unidades de Alimentação e Nutrição que apresentam alto poder de compra, beneficiando a unidade em relação à qualidade de seus alimentos e ao tempo para a produção. 
$\mathrm{O}$ descongelamento também deve ser realizado corretamente caso contrário leva a perdas nutricionais (OETTERER; SAVAY-DA-SILVA; GALVÃO et al., 2012) e multiplicação microbiana. As condições para sua realização são em temperaturas inferiores a $5^{\circ} \mathrm{C}$, ou em forno de micro-ondas quando o alimento for submetido imediatamente à cocção. Caso não forem utilizados imediatamente, os alimentos devem permanecer sob refrigeração, e não podem ser recongelados (BRASIL, 2004).

Vasconcelos e Filho (2010), e Gonçalves, Andrade e Souza (2010) apresentaram que o branqueamento é um método de conservação rápido, e quando realizado adequadamente, o mesmo mantém as características organolépticas do alimento por um período maior. Entretanto, o mesmo leva a perda de diversos nutrientes, por conta da imersão em água (SAGGIN, 2017; SOARES; JOSÉ, 2013; SOUZA FILHO et al., 1999). Dessa forma, o branqueamento não é um procedimento indicado, pois apesar de ser viável para Unidades de Alimentação e Nutrição, este leva a diversas perdas nutricionais, diminuindo o valor das refeições oferecidas.

Através desta análise, é possível alegar a viabilidade na realização de procedimentos que minimizem a perda de nutrientes durante a produção de refeições em Unidades de Alimentação e Nutrição. Esta ação também seria capaz de trazer vantagens às unidades, de modo que as refeições, ao serem mais ricas nutricionalmente, atraem uma maior clientela por conta da busca atual pela saúde através da alimentação saudável.

\section{CONCLUSÃO}

A ingestão de nutrientes é essencial para a saúde e bem-estar da população, entretanto, os alimentos podem passar por processos que diminuam suas concentrações, tendo como principais a cocção, o congelamento e o branqueamento. Os métodos que apresentam menores perdas nutricionais relacionadas a cocção foram o cozimento por vapor, através do forno combinado, sobre o congelamento, ocorreu apenas através do procedimento rápido, enquanto o branqueamento apresenta perdas nutricionais inevitáveis, sem mostrar maneiras que as diminuam.

Através da análise dos métodos, os equipamentos necessários e seus custos, foi possível afirmar a viabilidade na realização de procedimentos que minimizam a perda de nutrientes durante a produção nas Unidades de Alimentação e Nutrição. Podendo trazer mais benefícios a unidade, como futuras economias de água, mão de obra, entre outros, e um aumento no número de clientes, por conta da maior demanda por uma alimentação saudável. Todavia, existe uma grande escassez de estudos relacionados à realização destes procedimentos em unidades de alimentação e nutrição visando menor perda nutricional, demonstrando a necessidade de materiais novos que evidenciem sua importância. 


\section{REFERÊNCIAS}

ABREU, E. S. de; PINTO, A. M. de S.; SPINELLI, M. G. N. Gestão de unidades de alimentação e nutrição: um modo de fazer. São Paulo: Editora Metha Ltda, 2009.

ALVES, N. E. G. et al. Efeito dos diferentes métodos de cocção sobre os teores de nutrientes em brócolis (Brassica oleracea L. var. Italica). Revista do Instituto Adolfo Lutz, São Paulo, v. 70, p. 507-513, 2011.

ARAÚJO, Wilma M. C. et al. Alquimia dos alimentos. 3. ed. Brasília: Senac, 2014.

AZEREDO, H. M. C. Fundamentos de estabilidade de alimentos. 2. ed. Brasília: Embrapa, 2012.

BALL, G. F. M. Bioavailability and Analysis of Vitamins in Foods. 1 ed. Londres: Chapman \& Hall, 1998. Disponível em: https:/ /books.google.com.br/books?hl=ptBR\&lr $=\& \mathrm{id}=0$ XsiBAAAQBAJ\&oi $=$ fnd $\& p g=P R 11 \& d q=$ Bioavailability + and + anal ysis+of+vitamins+in+foods+pdf\&ots=u2zyr6ssNB\&sig=eaxHWG7keyfMj-sIfTiDy3Tqf_o\#v=onepage\&q\&f=false. Acesso em: 08 de jul. 2020.

BRASIL. Ministério da Agricultura, Pecuária e Abastecimento. Manual de hortaliças não convencionais / Ministério da Agricultura, Pecuária e Abastecimento. Secretaria de Desenvolvimento Agropecuário e Cooperativismo. Brasília: Mapa/ACS, 2010.

BRASIL. Ministério da Saúde. Secretaria de Atenção à Saúde. Departamento de Atenção Básica. Guia Alimentar para a População Brasileira/ Ministério da Saúde, Secretaria de Atenção à Saúde, Departamento de Atenção Básica. 2. ed. - Brasília: Ministério da Saúde, 2014.

BRASIL. Resolução RDC n $^{\circ} 216$ de 2004. Dispõe sobre Regulamento Técnico de Boas Práticas para Serviços de Alimentação. Diário Oficial da União: Poder Executivo, 16 set. 2004.

BRASIL. Portaria SIT/DSST n 3 de 01/03/2002. Baixa instruções sobre a execução do Programa de Alimentação do Trabalhador - PAT. Secretária de Inspeção do Trabalho, 2002.

CARNEIRO, Henrique. Comida e sociedade: uma história da alimentação. Estudos históricos, Rio de Janeiro, 2004, n. 33, p. 175-179, jan./jun. 2004.

CEARÁ. Secretaria da Educação. Tecnologia dos Alimentos. Fortaleza: Escola Estadual de Educação Profissional, 2013.

CESAR, L. Métodos de conservação de alimentos: Uso de Calor. Espírito Santo: Universidade federal do Espírito Santo, 2008. Disponível em: http:/ /www.agais.com/ tpoa1/curso/capitulo_3_tpoa1_met_conserva_2008_part1.pdf. Acesso em: 06 jul. 2020. 
CINTRA, P. Métodos de conservação de alimentos. Out. 2014. 52 slides. Disponível em: <https://nutrisaude14.files.wordpress.com/2014/11/mc3a9todos-deconservac3a7c3a3o-dos-alimentos-2014.pdf>. Acesso em: 06 de jul. e 2020.

COLLAÇO, Janine Helfst Leicht. Restaurantes de comida rápida, os fast-foods, em praças de alimentação de shopping centers: transformações no comer. Estudos Históricos. Rio de Janeiro, 2004, n. 33, p. 116-135, jan./jun. 2004.

CONGRESSO NORTE NORDESTE DE PESQUISA E INOVAÇÃO, 7., 2012, Tocantins. A relação da atividade física e alimentação saudável em busca da qualidade de vida. Palmas: Ciências da Saúde, 2012.

DAIUTO, Érica Regina et al. Estabilidade de Minerais em Hortaliças submetidas a diferentes métodos de cozimento. Nativa. São Paulo: v. 3, n. 2, p. 102-108, abr./jun. 2015 .

DANG, J.; ARCOT, J.; SHRESTHA, A., Folate retention in selected processed legumes. Food Chemistry, Austrália, v. 68, p. 295-298, 2000. Disponível em: https: / / www. sciencedirect.com/science/article/abs/pii/S0308814699002022. Acesso em: 07 de jul. 2020 .

EVANGELISTA, J. Tecnologia de Alimentos, 2. ed., São Paulo: Editora Atheneu, 2000.

ESTELLES; R. S. Importância do controle da temperatura e do tratamento térmico na preservação dos nutrientes e da qualidade dos alimentos. Monografia (Especialização em Qualidade em Alimentos) - Universidade de Brasília, Brasília, 2003. Disponível em: https://bdm.unb.br/bitstream/10483/246/1/2003_ RenataSoaresEstelles.pdf. Acesso em: 07 jul. 2020.

FELLOWS, P. J. Tecnologia do Processamento de Alimentos: princípios e prática. 2 ed. Porto Alegre: Artemed, 2006.

GAVA, A. J; FRIAS, J. R.G; SILVA, C.A.B. Tecnologia de alimentos: princípios e aplicações. 1. ed. São Paulo: Nobel, 2008.

GERMANO, P. M. L.; GERMANO, M. I. S. Higiene e Vigilância Sanitária de Alimentos. 4. ed. Barueri: Manole, 2011.

GONÇALVES, S. S.; ANDRADE, J. S.; SOUZA, R. S. Influência do branqueamento nas características físico químicas e sensoriais do abacaxi desidratado*. Alimentos e Nutrição, Araraquara, v. 21, n. 4, p. 651- 657, out./dez. 2010. Disponível em: https:/ / docplayer.com.br/52429444. Influencia-do-branqueamento-nas-caracteristicas-fisicoquimicas-e-sensoriais-do-abacaxi-desidratado.html. Acesso em: 07 jul. 2020.

INSTITUTO AMERICANO DE CULINÁRIA. Chef profissional. 4. ed. São Paulo: Senac, 2011.

LIVERA, A. V. S.; SALGADO, S. M. Técnica dietética: um guia prático. Recife: Ed. Universitária da UFPE, p. 176, 2007. 
MCGEE, H. Comida e Cozinha: Ciência e Cultura da Culinária. 2. ed. São Paulo: WMF Martins Fontes, 2014.

MELO, M. M. D.; SOUZA, F. J. V.; ARAÚJO, A. O. Custos da qualidade: um estudo em um restaurante de grande porte da cidade de Natal -RN. Rio Grande do Norte: Revista UNIABEU, v. 6, n. 12, p. 218-233, jan./abr. 2013.

MONTEIRO, Jordanna Santos. Determinação das melhores técnicas de cocção para aceitabilidade de hortaliças. 2014. Trabalho de Conclusão de Curso (Graduação em Nutrição) - Departamento de Nutrição da Faculdade de Ciências da Saúde da Universidade de Brasília. Brasília, 2014.

NESPOLO, C. R. et al. Práticas em tecnologia de alimentos. 1. ed. Porto Alegre: Artmed, 2015.

NONINO, C. B.; FERREIRA, C. N.; TANAKA, N. Y. Y. Planejamento Físico-funcional, In: VIEIRA, M. C. M; JAPUR, C. C. Gestão de Qualidade na produção de refeições. 1. ed. Rio de Janeiro: Guanabara Koogan, 2012.

OETTERER, Marília et al. Fundamentos de Ciência e tecnologia de alimentos. 1. ed. Barueri: Manole, 2006.

OETTERER, Marília; SAVAY-DA-SILVA, Luciana Kimie; GALVÃO, Juliana Antunes. Congelamento é o melhor método para a conservação do pescado. Visão Agrícola. São Paulo, n. 11, p 137-139, dez 2012.

PHILIPPI, Sonia Tucunduva. Pirâmide dos Alimentos. 2. Ed. Barueri: Manole, 2014.

PIGOLI, D. R. Alterações nutricionais em hortaliças decorrentes de diferentes métodos de cozimento. Dissertação (Mestrado em Agronomia/Ciências Agronômicas na especialidade de energia na agricultura) - Universidade Estadual Paulista "Júlio de Mesquita Filho", Botucatu, 2012.

PROENÇA, Rossana Pacheco da Costa. Inovações tecnológicas na produção de refeições: conceitos e aplicações básicas. 3. ed. São Paulo: Insular, 2009.

SAGGIN, Samara de Fátima. Avaliação Físico-Química de Hortaliças Orgânicas Congeladas. 2017. Trabalho de Conclusão de Curso (Graduação em Nutrição) Universidade Regional do Noroeste do Estado do Rio Grande do Sul, Rio Grande do Sul, 2017.

SANTOS, M. A. T.; ABREU, C. M. P.; CARVALHO, V. D. Efeito de diferentes tempos de cozimento nos teores de minerais em folhas de brócolis, couve-flor e couve (Brassica oleracea L.). Ciênc. agrotec. [online], Lavras, v. 27, n. 3, 0. 597-604, maio/jun, 2003.

SILVA, J. A. Tópicos da tecnologia dos alimentos. 1. ed. Brasil: Livraria varela, 2000. 
SOARES, L. P.; JOSÉ, A. R. S. Compostos bioativos em polpas de mangas "rosa" e "espada" submetidas ao branqueamento e congelamento. Revista Brasileira de Fruticultura, Jaboticabal, v. 35, n. 2, p. 579-586, jun. 2013.

SOUZA, Michele C. et al. Emprego do frio na conservação de alimentos. Enciclopédia Biosfera, Goiânia, v. 9, n. 16, p. 1027-1046, 2013. Disponível em: https:/ /www. conhecer.org.br/enciclop/2013a/agrarias/EMPREGO\%20DO\%20FRIO.pdf. Acesso em: 10 jul. 2020.

SOUZA FILHO, M. S. M. et al. Efeito do branqueamento, processo osmótico, tratamento térmico e armazenamento na estabilidade da vitamina $C$ de pedúnculos de caju processados por métodos combinados. Ciênc. Tecnol. Alim.[online], v. 19, n. 2, p. 211-213, 1999. Disponível em: https: / / www.scielo.br/scielo. php?pid=S010120611999000200010\&script=sci_abstract\&tlng=pt. Acesso em: 07 jul. 2020.

VASCONCELOS, M. A. S.; FILHO, A. B. M. Conservação de alimentos. Ministério da Educação: Escola Técnica Aberta do Brasil, 2010. Disponível em: http:/ / redeetec.mec. gov.br/images/stories/pdf/eixo_prod_alim/tec_alim/181012_con_alim.pdf. Acesso em: 07 jul. 2020.

VELHO, Liana Cleide Flor de Lima. Avaliação da Retenção de Nutrientes, Aspectos Sensoriais e Microbiológicos de Batata-doce (ipomoea batatas (L.) Lam.) Submetida a Diferentes Métodos de Cocção. 2016. Tese (Mestrado em Ciência e Tecnologia de Alimentos) - Centro de Ciências Agrárias da Universidade Federal do Ceará, Fortaleza, 2016.

WORLD HEALTH ORGANIZATION/WHO. Burden: mortality, morbidity and risk factors. In: WHO. Global status report on noncommunicable diseases 2010. Genebra: WHO, 2011. p. 9-31. Disponível em: https:/ / www.who.int/nmh/publications/ncd_report_chapter1.pdf. https:/ / apps.who.int/iris/bitstream/handle/10665/44579/9789240686458_eng. pdf;jsessionid=12EF08A546401BD34CB65168154C2CFB? sequence=1. Acesso em: 30 jun. 2020. 